\title{
APLICAÇÃO DO SOFTWARE FIRE DYNAMICS SIMULATOR (FDS) NO ESTUDO DA SEGURANÇA CONTRA INCÊNDIOS (SCI) NO BRASIL
}

\author{
Roberta Tabaczenski ${ }^{1}$ \\ Cristiano Corrêa ${ }^{2}$ \\ Marina Machado Leal dos Santos ${ }^{3}$ \\ Tiago Ancelmo de Carvalho Pires ${ }^{4}$ \\ José Jeferson Rêgo Silva ${ }^{5}$
}

\section{RESUMO}

Este artigo apresenta o software Fire Dynamics Simulator (FDS), desenvolvido pelo National Institute of Standards and Technology (NIST), como um instrumento auxiliar no estudo da Segurança Contra Incêndios (SCl). Para isso, foi realizada uma revisão dos trabalhos recentes que foram publicados no Brasil. Estes trabalhos utilizaram este simulador para reconstruir incêndios ocorridos ou para executar simulações prognósticas. Estas simulações são importantes, pois, projetistas e técnicos de combate a incêndio podem se basear para aferir as dinâmicas e características tanto de um incêndio ocorrido quanto de um possível sinistro. Com esta revisão bibliográfica faz se a análise das potencialidades e limitações inerentes a tal ferramenta na reprodução de incêndios reais, para auxiliar trabalhos futuros desenvolvidos com o mesmo. Conclui-se que este software de fluidodinâmica computacional vem sendo usado de forma bastante promissora, tanto em investigações de incêndios havidos, como para tornar os projetos e planejamentos de resposta mais eficazes. Contudo é importante compreender que apesar das muitas sofisticações deste programa, os modelos desenvolvidos devem ser cuidadosamente calibrados para que os resultados sejam compatíveis com a realidade simulada.

Palavras chave: Segurança Contra Incêndio (SCI); Simulação computacional de incêndios; Fire Dynamics Simulator (FDS).

\footnotetext{
${ }^{1}$ Mestranda em Engenharia Civil - com ênfase em Segurança Contra Incêndio pela Universidade Federal de Pernambuco. E-mail: robertatdesa@gmail.com

${ }^{2}$ Oficial do Corpo de Bombeiros Militar de Pernambuco. Doutorando em Engenharia Civil - com ênfase em Segurança Contra Incêndio pela Universidade Federal de Pernambuco. E-mail: cristianocorreacbmpe@gmail.com

${ }^{3}$ Mestranda em Engenharia Civil - com ênfase em Segurança Contra Incêndio pela Universidade Federal de Pernambuco. E-mail: mmls.marina@gmail.com

${ }^{4}$ Doutor em Engenharia de Segurança Contra Incêndio - Universidade de Coimbra - PT. Professor do Departamento de Engenharia Civil da Universidade Federal de Pernambuco. E-mail: tacpires@yahoo.com.br

${ }^{5}$ Doutor em Engenharia de Segurança Contra Incêndio - Wessex Institute Of Technology Portsmouth University, WIT, Grã-Bretanha. Professor do Departamento de Engenharia Civil da Universidade Federal de Pernambuco. Email: jjrs@ufpe.br
} 


\title{
FIRE DYNAMICS SIMULATOR (FDS) SOFTWARE APPLICATION IN THE STUDY OF FIRE SAFETY IN BRAZIL
}

\begin{abstract}
This paper presents the Fire Dynamics Simulator (FDS) software, developed by the National Institute of Standards and Technology (NIST), as an auxiliary tool in the study of Fire Safety. For that, a review of recent research papers published in Brazil was carried out. These studies used this simulator to reconstruct occurred fires or to perform prognostic simulations. Simulations are important because designers and fire-fighting technicians can rely on the dynamics and characteristics of both a fire and a possible fire. This bibliographical review allows the analysis of the potentialities and limitations inherent to such tool in the reproduction of real fires in order to help future works developed with it. It is concluded that this software of computational fluid dynamics has been used in a very promising way for fire investigations, to make projects and firefighting more efficient. However it is important to understand that despite the many sophistications of this program the developed models must be carefully calibrated so that the results are compatible with reality.
\end{abstract}

Keywords: Fire Safety; Computational fire simulation; Fire Dynamics Simulator (FDS).

\section{Artigo recebido em 30/07/17 e Aceito em 23/10/17}

\section{INTRODUÇÃO}

Atualmente, observa-se que a grande maioria dos estudos desenvolvidos na área de Segurança Contra Incêndios (SCl) no Brasil são voltados para a análise do comportamento de elementos estruturais e 
construtivos submetidos a altas temperaturas isoladamente. Nestes estudos, a representação do incêndio é feita através de curvas padronizadas internacionalmente. Entretanto, apesar de serem largamente usadas em ensaios para avaliar o Tempo Requerido de Resistência ao Fogo (TRRF) das estruturas, estas curvas não são capazes de representar o desenvolvimento de incêndios reais, visto que, o comportamento deste fenômeno depende de inúmeras variáveis, que tornam cada evento único e com características próprias. (COSTA e SILVA, 2006). Além disso, em incêndios reais, há também liberação de fumaça e gases tóxicos que se tornam determinantes para a sobrevivência humana, pois, em caso de incêndios, são estas as maiores causas imediatas de mortes. (SEITO et al., 2008).

$\mathrm{O}$ estudo do comportamento de incêndios reais é uma vertente da $\mathrm{SCl}$ de suma importância que pode ainda dar origem a outras pesquisas, como a avaliação da propagação do incêndio em edificações, comportamento do incêndio quando sujeito ação de sprinklers e outros elementos de proteção ativa, eficiência da utilização de sistemas construtivos, estruturais e de acabamentos que visam à contenção de incêndios (proteção passiva), determinação de rotas de fuga, layouts mais eficientes na contenção de incêndios, dimensão e localização de aberturas averiguação de hipóteses de origem e possíveis causas de incêndios em edificações, estimação de curvas de temperaturas, altura da camada de fumaça, dentre outros.

Entretanto, os riscos e o alto custo dos equipamentos e das instalações necessárias para a realização de experimentos que envolvam edificações completas para avaliação do comportamento de incêndios tornam esse tipo de pesquisa escassa no mundo e praticamente inexistente no Brasil. (RUSCHEL, 2011; CUNHA, 2016). Desta forma, a utilização de softwares para simulação computacional de incêndios vem se tornando uma solução cada vez recorrente em pesquisas de $\mathrm{SCl}$. 
Em suma, estes softwares podem ser baseados no modelo de zonas, como o OZone e o Consolidated Model of Fire and Smoke Transport (CFAST), ou de fluidodinâmica computacional (em inglês Computational Fluid Dynamics, CFD), como o SMARTFIRE e o Fire Dynamics Simulator (FDS), e tem por objetivo principal representar o comportamento de incêndios reais através de, dentre outros parâmetros, temperaturas, movimentação de fumaça e concentração de oxigênio no ambiente simulado.

Dentre esses, o FDS é o software de simulação de incêndios mais utilizado em pesquisas acadêmicas e técnicas, e consequentemente o mais rico em literatura disponível. Desde o início da sua divulgação o FDS vem sendo amplamente utilizado em estudos de $\mathrm{SCl}$ no mundo. No Brasil, as primeiras publicações de pesquisas realizadas com o auxilio deste software datam o ano de 2008 e, aos poucos este tem ganhado espaço no meio acadêmico-científico como ferramenta para auxiliar estudos voltados para diversas áreas da SCl.

Neste contexto, este artigo tem por objetivo relacionar as potencialidades desta ferramenta exploradas pelos pesquisadores brasileiros. Para isso, será realizada uma breve descrição do software, e posteriormente serão expostos os trabalhos desenvolvidos com o seu auxilio, desde o início de sua utilização até os dias atuais. Espera-se que este trabalho possa contribuir para a difusão do conhecimento a cerca desta ferramenta entre os pesquisadores e técnicos na área de $\mathrm{SCl}$ no Brasil.

\section{FIRE DYNAMICS SIMULATOR (FDS)}

O Fire Dynamics Simulator (FDS) é um software de fluidodinâmica computacional (em inglês Computational Fluid Dynamics, CFD) desenvolvido pelo National Instituteof Standards and Technology dos Estados Unidos da América (NIST/EUA), que resolve numericamente as equações de NavierStokes adequada para fluxo de baixa velocidade movido termicamente, com 
Revista Científica do Corpo de Bombeiros Militar de Pernambuco

Seção 1 - Artigos Técnico Científicos

Artigo publicado no Vol.03 №7 - Edição de JUL a DEZ 2017 - ISSN 2359-4829

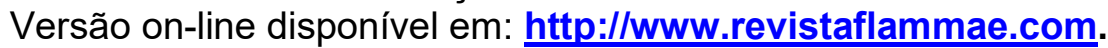

ênfase no transporte de fumaça e calor provocados por incêndios (MCGRATTAN et al., 2016).

Sua versão mais recente é a 6.5.3, e está disponível para os sistemas operacionais Windows, Linux e Mac OS X. Seu pacote de instalação inclui o programa Smokeview (SMV), também desenvolvido pelo NIST, um programa de visualização criado para reproduzir animações da propagação do fogo e fumaça, concentrações de gás e de crescimento e movimento de fumaça em toda a estrutura submetida à simulação, ambos disponibilizados gratuitamente no site do desenvolvedor (https://pages.nist.gov/fds-smv/downloads.html).

Devido ao software não dispor de interface gráfica, os dados de entrada são inseridos pelo usuário através de linhas de comando em um único arquivo de entrada, através de um editor de texto que deve conter todas as informações do modelo, tais como: título da simulação, dimensões do domínio computacional, divisões da malha, tempo de simulação, condições iniciais do ambiente, propriedades dos materiais combustíveis e incombustíveis, condições de combustão, outputs desejados, dentre outros. O programa entende como comando os caracteres escritos entre os símbolos " $\&$ " e "l", cujos dados necessários para a análise são especificados no arquivo de entrada usando uma lista de comandos com formatos pré-definidos em sua programação (namelist).

Ao final da criação do arquivo de entrada, o usuário deve salva-lo no formato nome.fds e abri-lo com o FDS para que o programa possa executar o processamento, este por sua vez, ocorre em modo MS-DOS e o usuário é informado apenas do tempo transcorrido da simulação. No decorrer do processamento, o programa cria automaticamente diversos arquivos de saída em formatos distintos, dentre eles arquivos tabulados (organizados em linhas e colunas, separados por vírgulas e visualizáveis por meio de editores de planilhas eletrônicas) e de visualização gráfica através do SMV. (CUNHA, 2016). 
É importante salientar que, por ser um programa de código fonte aberto, - FDS facilita a identificação de possíveis erros em sua estruturação, culminando em seu aperfeiçoamento e estimulando várias instituições a dedicar-se no desenvolvimento de plataformas que facilitem o uso do software, além de acoplar os seus resultados em módulos para outros estudos. A exemplo disto menciona-se os softwares: PyroSim, desenvolvido pela Thunderhead Engineering Consultants, que funciona como uma interface gráfica de entrada do FDS, auxiliando o usuário no desenvolvimento de modelos de incêndio; e Evac, desenvolvido pelo Technical Research Centre of Finland (VTT), que é um módulo de simulação de evacuação de pessoas que pode ser acoplado aos modelos de incêndios do FDS.

\section{TRABALHOS DESENVOLVIDOS NO BRASIL COM O AUXILIO DO FDS}

No Brasil, apesar dos estudos em SCl serem embrionários e a utilização de simuladores de incêndios ainda não ser muito difundida, o FDS tem ganhado espaço nos últimos anos, provando ser uma ferramenta adequada para auxiliar estudos voltados para diversas finalidades, como: definição de projetos arquitetônicos mais eficientes do ponto de vista de SCI (ALVES et al., 2008), avalição da eficiência da utilização de sistemas construtivos que visam à contenção de incêndios (RODRIGUES, 2009; CUNHA, 2016), reconstituição de incêndios e avaliação de edificações sinistradas (RUSCHEL, 2011; BRAGA E LANDIM, 2008), análise de segurança de instalações sensíveis como túneis rodoviários em situação de incêndio (CARVALHO, 2013), avaliação da propagação do incêndio em edificações (BRUNETTO, 2015), averiguação de hipóteses da origem de incêndios em edificações (MAZZONI e KLEIN, 2015), estimação de curvas de temperaturas de incêndios (CENTENO et al., 2015; TABACZENSKI et al., 2017; KIRYU, 2017), análise do comportamento de incêndios (CENTENO et al., 2015; MATOS, 2017), estimação do tempo 
Revista Científica do Corpo de Bombeiros Militar de Pernambuco

Seção 1 - Artigos Técnico Científicos

Artigo publicado no Vol.03 №7 - Edição de JUL a DEZ 2017 - ISSN 2359-4829

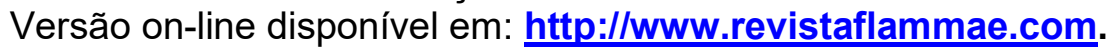

facultado para evacuação de edificações e da altura da camada livre de fumaça (CARLOS et al., 2016; MARIANI e CARLOS, 2016), avaliação de tanques de combustíveis em situação de incêndio (HAUSER, 2016), dentre outros.

Alves et al. (2008) realizaram um estudo com um prédio comercial de escritórios com características típicas e representativas das edificações brasileiras, cujo objetivo foi aplicar a simulação computacional de incêndios para verificar a influência da fumaça nas rotas de fuga. Para isso, os autores elaboraram o projeto arquitetônico desta edificação atendendo as prescrições das normas brasileiras de $\mathrm{SCl}$ e, posteriormente realizaram simulações computacionais nos softwares FDS e SIMULEX (desenvolvido pela empresa IES, do Reino Unido), a fim de determinar a influência da fumaça e da temperatura na evacuação de pessoas e a eficiência das orientações normativas.

Com este estudo, Alves et al. (2008) demonstrou que a simulação computacional de incêndios é um recurso que pode auxiliar na fase de projeto de edificações, ajudando a definir layouts, melhor posicionamento de escadas de emergência, portas corta-fogo e outros parâmetros fundamentais para assegurar a segurança de seus ocupantes. Para os autores, este recurso pode contribuir para a minimização dos efeitos danosos dos incêndios antes mesmo de ocorrerem.

Braga e Landim (2008) realizaram uma investigação de um incêndio ocorrido em uma unidade residencial na cidade de Brasília, no ano de 2007, cujo objetivo foi testar as hipóteses de origem do fogo. Para isso, foi desenvolvido no software FDS um modelo representativo da geometria, propriedades térmicas e carga de incêndio deste ambiente. (BRAGA e LANDIM, 2008).

Para os autores, "apesar de cada incêndio possuir particularidades, há um padrão de comportamento entre os incêndios ocorridos em ambientes com características construtivas e cargas de incêndio semelhantes". (BRAGA e 
LANDIM, 2008). Sendo assim, antes de averiguar um incêndio, o investigador deve ter conhecimentos sobre o comportamento do fogo nos diversos tipos de edificação, para que possa analisar corretamente seus vestígios deixados pelo sinistro.

Braga e Landim (2008) afirmam que a simulação computacional é uma importante ferramenta que pode auxiliar investigadores na compreensão de incêndios, uma vez que propicia a execução de diversos testes de hipóteses elaboradas. No entanto, é importante saber que esta ferramenta não trará todas as respostas sobre o sinistro.

Com este estudo, Braga e Landim (2008) observaram que a simulação do incêndio através do FDS desenvolveu características que coincidiram perfeitamente com as fotografias da residência após a ocorrência do sinistro. Além disso, verificaram que na ocorrência da generalização do incêndio, as temperaturas dentro do ambiente podem ter ultrapassado $1.000^{\circ} \mathrm{C}$.

Rodrigues (2009) desenvolveu uma pesquisa cujo objetivo foi analisar a eficiência do sistema de compartimentação vertical externa por afastamento entre as janelas e por implantação de projeções horizontais como continuidade dos pisos, segundo as exigências das normas brasileiras. Para isso, foram realizadas simulações computacionais através do FDS e ensaios de campo em escala reduzida com diferentes configurações de fachadas e cargas de incêndio para comparação dos resultados obtidos. A Figura 2 mostra a geometria de um dos modelos desenvolvidos em campo e na simulação computacional deste estudo. 


\section{Revista FLAMMAE}

Revista Científica do Corpo de Bombeiros Militar de Pernambuco

Seção 1 - Artigos Técnico Científicos

Artigo publicado no Vol.03 Nº7 - Edição de JUL a DEZ 2017 - ISSN 2359-4829

Versão on-line disponível em: http://www.revistaflammae.com.

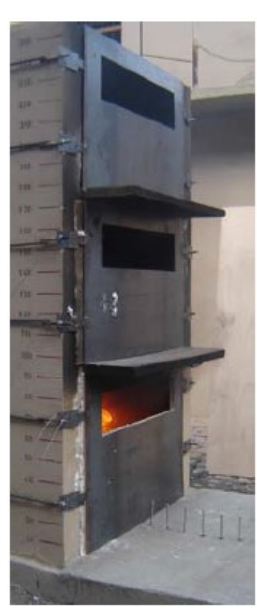

(1)

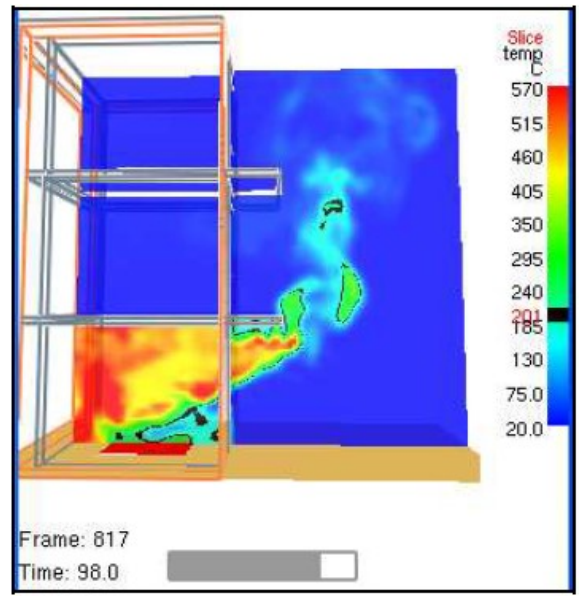

(2)

Figura 2 - Geometria de um dos modelos de compartimentação vertical estudados por Rodrigues (2009): (1) modelo experimental em escala reduzida, (2) modelo computacional desenvolvido no FDS.

Fonte: Rodrigues, 2009.

Com este estudo, Rodrigues (2009) constatou que a geometria da edificação e das aberturas podem modificar a dinâmica de propagação do fogo. Além disso, na maioria dos casos a compartimentação externa funciona como barreira para a propagação do incêndio para os pavimentos superiores da edificação.

Para Rodrigues (2009), o FDS é uma ferramenta potente capaz de prever corretamente o comportamento de incêndios, servindo de embasamento para avaliação da eficiência de sistemas de proteção passiva e confecção de pareceres técnicos sem os custos advindos de ensaios experimentais. Entretanto, para que isso seja possível, é necessário que sejam realizados estudos de caracterização das propriedades dos materiais comumente utilizados no Brasil para que os modelos computacionais desenvolvidos possam representar mais adequadamente a realidade do país.

Ruschel (2011) simulou computacionalmente, através dos softwares PyroSim e FDS, o incêndio ocorrido no Shopping Total, localizado na cidade em Porto Alegre/RS, no ano de 2007, a fim de reproduzir as características 
Revista Científica do Corpo de Bombeiros Militar de Pernambuco

Seção 1 - Artigos Técnico Científicos

Artigo publicado no Vol.03 №07 - Edição de JUL a DEZ 2017 - ISSN 2359-4829

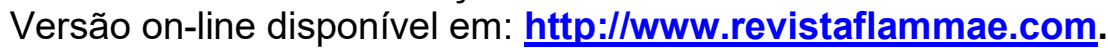

reais do sinistro, que foram estimadas baseadas em ensaios de difratometria de raios-x de amostras de pó de diversos elementos da estrutura, extraídas após a ocorrência do mesmo. Posteriormente a autora realizou uma avaliação da edificação considerando uma situação hipotética com a ação de sprinklers durante o sinistro. A Figura mostra a edificação antes do sinistro, bem como o modelo computacional desenvolvido para este estudo.

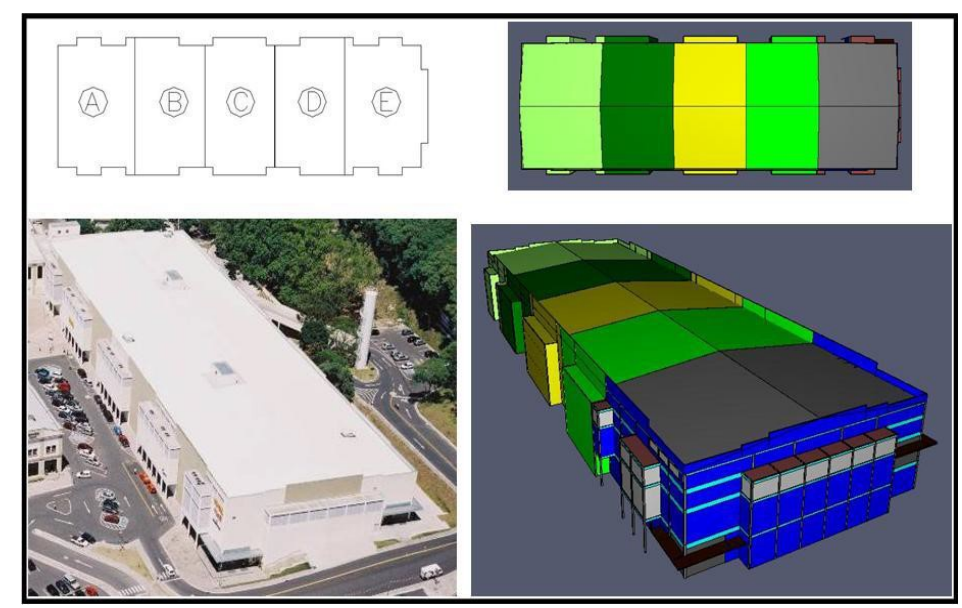

Figura 3 - Edificação estudada por Ruschel (2011): foto do prédio antes do sinistro (esquerda) e modelo desenvolvido para a simulação computacional (direita).

Fonte: Ruschel, 2011.

A autora relata que, durante $\mathrm{o}$ desenvolvimento do modelo computacional foi percebida uma carência de referencial bibliográfico contendo informações a respeito do desempenho e das características térmicas de diversos materiais presentes na edificação, e dos critérios a serem adotados nas simulações. (RUSCHEL, 2011).

Apesar disso, após a devida calibração do modelo, os resultados obtidos se mostram coerentes com os indícios verificados na estrutura sinistrada, mostrando que, se os parâmetros forem ajustados adequadamente, a simulação computacional pode auxiliar na compreensão do comportamento de incêndios em diferentes cenários de uma edificação, sem o alto custo das 
Revista Científica do Corpo de Bombeiros Militar de Pernambuco

Seção 1 - Artigos Técnico Científicos

Artigo publicado no Vol.03 No07 - Edição de JUL a DEZ 2017 - ISSN 2359-4829

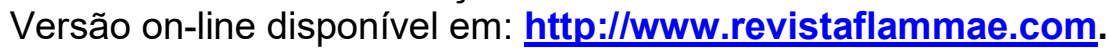

instalações e equipamentos geralmente empregados em estudos experimentais. (RUSCHEL, 2011).

Fontenelle (2012) desenvolveu um trabalho cujo objetivo foi avaliar a segurança de tanques metálicos de armazenamento de etanol em situação de incêndio, bem como avaliar a eficácia das medidas de segurança, adotadas e prescritas por norma, nos parques de tancagem das indústrias. Para isso a autora desenvolveu um modelo computacional no FDS de um parque de tancagem hipotético para verificar os efeitos que um incêndio originado em um tanque totalmente preenchido com etanol provocaria nos tanques vizinhos. Este modelo foi submetido a quatro situações hipotéticas, sendo elas: com e sem a incidência de vento e, com e sem sistema de dilúvio nos tanques.

Com este estudo Fontenelle (2012) verificou que a distância de segurança entre tanques é insuficiente de acordo com as normas brasileiras, principalmente em regiões cuja condição de vento não é nula, e, em regiões com condição de vento igual ou superior a $5 \mathrm{~m} / \mathrm{s}$, o sistema de dilúvio atrelado às distâncias recomendadas por normas, pode não ser suficiente para evitar a propagação do incêndio entre os tanques de combustível vizinhos.

Carvalho (2013) avaliou o comportamento de incêndios em tuneis rodoviários sob condições de ventilação nula e forçada, com o intuito de verificar a influência da ventilação no desenvolvimento do incêndio neste tipo de construção. Para isso, desenvolveu-se um modelo computacional no FDS de um túnel com características semelhantes as do Túnel Rebouças, localizando na cidade do Rio de Janeiro/RJ, considerando a situação hipotética de um veiculo de porte médio estar pegando fogo no interior do túnel e, a partir dos resultados foi avaliado a evolução de temperaturas, concentração de gases e o fluxo de calor no interior do túnel estudado.

Com este estudo, Carvalho (2013) afirma que, apesar da semelhança do comportamento da movimentação dos fluidos em ambos os casos de ventilação propostos, as temperaturas encontradas e o fluxo de calor gerado 
Revista Científica do Corpo de Bombeiros Militar de Pernambuco

Seção 1 - Artigos Técnico Científicos

Artigo publicado no Vol.03 №7 - Edição de JUL a DEZ 2017 - ISSN 2359-4829

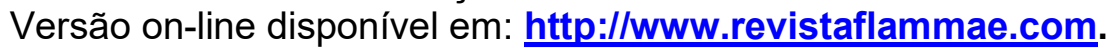

pela radiação, quando considerada a existência de um sistema de ventilação forçada é favorável aos usuários do túnel. Entretanto, quanto à presença de fumaça, concluiu-se que a ventilação forçada é não é favorável aos usuários do túnel. (CARVALHO, 2013).

Brunetto (2015) realizou um estudo prognostico de incêndio em uma instituição de ensino superior através da simulação computacional nos softwares PyroSim e FDS. Para isso, foram testadas quatro situações hipotéticas para o acontecimento do sinistro, nas quais foram alteradas a localização do início do incêndio e a configuração de ventilação da edificação. Nestas simulações foram aferidas medições de temperaturas e liberação de energia, além dos dados visuais fornecidos pelo SMV, tais como: velocidade da movimentação do ar, movimento e propagação do fogo e da fumaça e perfis de temperaturas. A Figura mostra o modelo computacional desenvolvido para este estudo.

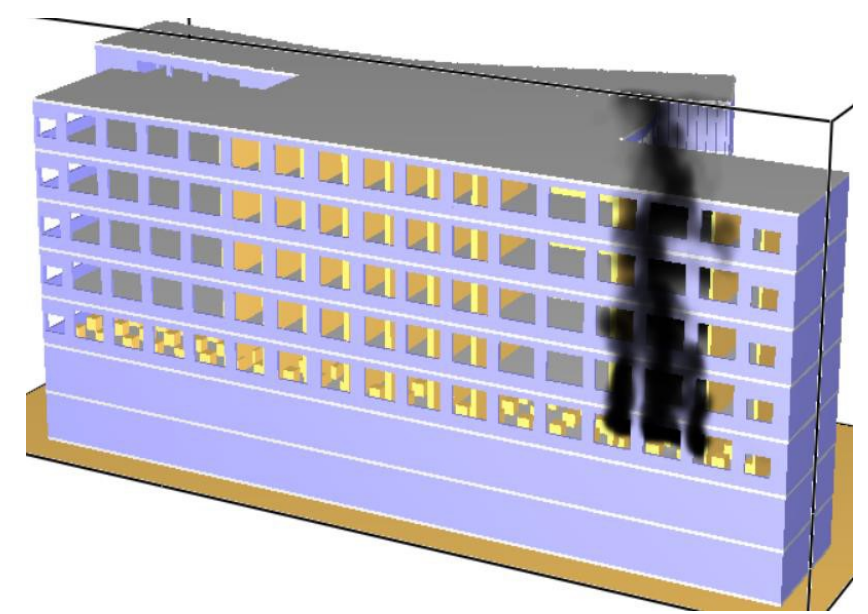

Figura 4- Modelo computacional desenvolvido por Brunetto (2015).

Fonte: Brunetto, 2015.

Com as simulações realizadas, Brunetto (2015) observou que em situações em que a edificação possuiria uma configuração de ventilação livre (com janelas abertas), a propagação do fogo ocorreria de forma mais acelerada 
do que em uma situação de janelas fechadas, resultando em um tempo de evacuação segura insuficiente para os usuários da instituição. Concluiu-se também que esta edificação não apresentaria segurança para a evacuação dos usuários em uma situação de incêndio, uma vez que toda a fumaça seria conduzida rapidamente para a escadaria do prédio (a única rota de saída da edificação). (BRUNETTO, 2015).

Com este estudo, o autor pode observar a movimentação e propagação das chamas e da fumaça em toda a edificação estudada. Assim, foi possível apresentar algumas soluções que visam à segurança dos ocupantes da instituição de ensino em uma situação de incêndio, tais como: a implantação de sistemas de detecção de fumaça e alarme de incêndio e recomendação da locação de escadas e saída de emergências. (BRUNETTO, 2015).

Mazzoni e Klein (2015) realizaram um estudo com o objetivo testar a hipótese apontada por peritos, da provável causa do sinistro ocorrido no Edifício Cacique, situado na cidade de Porto Alegre/RS, no ano de 1996. Para isso, os autores desenvolveram um modelo tridimensional do edifício nos softwares AutoCad, importam esta geometria para o software PyroSim, e posteriormente realizaram a simulação do incêndio no software FDS. A Figura 3 mostra o edifício analisado, bem como o modelo desenvolvido pra realização da simulação computacional. 


\section{Revista FLAMMAE}

Revista Científica do Corpo de Bombeiros Militar de Pernambuco

Seção 1 - Artigos Técnico Científicos

Artigo publicado no Vol.03 Nº7 - Edição de JUL a DEZ 2017 - ISSN 2359-4829

Versão on-line disponível em: http://www.revistaflammae.com.

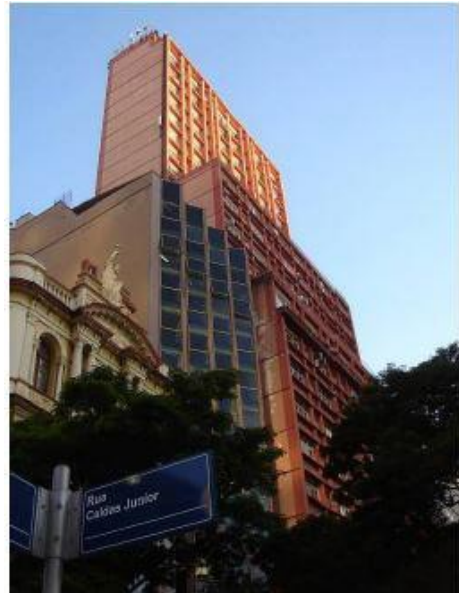

(1)

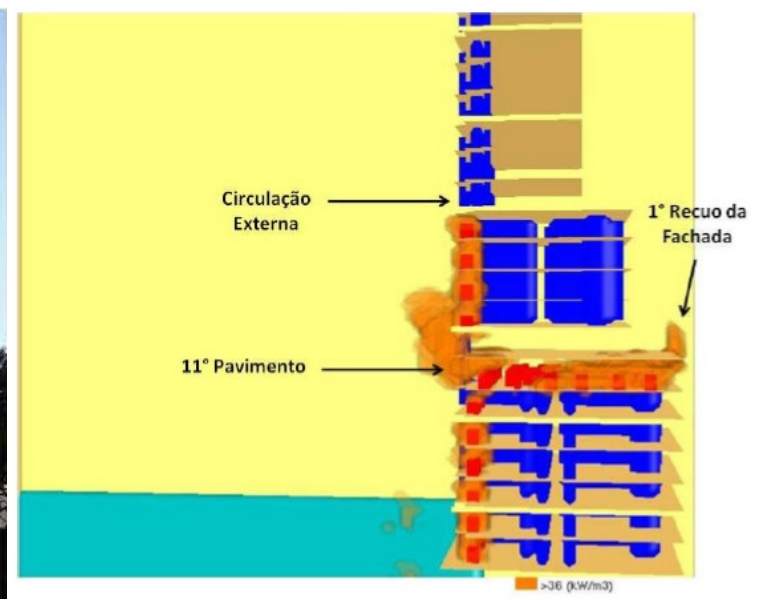

(2)

Figura 3 - Edificação estudada por Mazzoni e Klein (2015): (1) foto do Edifício Cacique antes do incêndio, (2) desenvolvimento inicial do incêndio na simulação computacional.

Fonte: Mazzoni e Klein, 2015.

Com este estudo, Mazzoni e Klein (2015) concluíram que os resultados da simulação realizada no FDS foram coerentes com os danos provocados pelo incêndio ocorrido no edifício, confirmando a hipótese levantada pela perícia. Além disso, os autores observaram que recuos existentes na fachada frontal da edificação bem como as circulações externas presentes em alguns pavimentos, contribuíram para o afastamento das chamas, evitando a propagação do fogo nestes pavimentos.

Para os autores os softwares FDS e PyroSim são ferramentas que podem auxiliar a produção de laudos técnicos sobre incêndios, uma vez que a visualização do comportamento do incêndio e dos resultados obtidos permite uma comparação com as informações colhidas junto às testemunhas, facilitando a análise das hipóteses formuladas. (MAZZONI e KLEIN, 2015).

Centeno et al. (2015) desenvolveram um modelo computacional de um incêndio de poça (em inglês pool fire) confinado em um ambiente residencial, baseado em um trabalho experimental encontrado na literatura. $\mathrm{O}$ objetivo foi comparar as medições de temperatura ao longo do tempo e demonstrar a confiabilidade dos resultados obtidos através da simulação computacional de 
Revista Científica do Corpo de Bombeiros Militar de Pernambuco Seção 1 - Artigos Técnico Científicos

Artigo publicado no Vol.03 №7 - Edição de JUL a DEZ 2017 - ISSN 2359-4829

Versão on-line disponível em: http://www.revistaflammae.com.

incêndios no FDS. Para os autores, "o FDS é recomendado por sua grande variedade de aplicações em proteção contra incêndios ou problemas térmicos com escoamento de fluidos", apresentando um modelo de combustão eficiente que descrevem satisfatoriamente a propagação do fogo em edifícios.

Quanto as malhas utilizadas em simulações computacionais de fluidodinâmica, Centeno et al. (2015) afirmam que "é sempre importante a verificação da discretização geométrica do domínio físico em relação à quantidade de volumes de controle que este está sendo dividido", sendo assim foram desenvolvidos três modelos, com malhas refinada $(4 \mathrm{~cm}$ de aresta), média (5 cm de aresta), e grosseira (10 cm de aresta), para comparação dos resultados obtidos.

Com este estudo, Centeno et al. (2015) observaram que o perfil de temperatura obtido com o FDS com a malha refinada teve concordância com os resultados experimentais, demonstrando a capacidade do software em reproduzir o incêndio estudado. No entanto, os resultados obtidos através das malhas: média e grosseria, apresentaram oscilações maiores em relação ao estudo experimental, mostrando a importância do refinamento da malha no estudo de incêndios neste programa. Segundo os autores, incêndios são compostos por diversos fenômenos físicos acoplados que tornam sua natureza fenomenologicamente oscilatória. Sendo assim, as flutuações nas medições de temperatura apresentadas tanto no estudo experimental encontrado na literatura quanto no modelo computacional desenvolvido representam esta natureza, demonstrando a capacidade do software prever este tipo de fenômeno. (CENTENO et al., 2015).

Cunha (2016) desenvolveu uma pesquisa cujo objetivo foi analisar o desempenho da compartimentação horizontal seletiva a fim de efetuar melhorias na Segurança Contra Incêndio em Edificações (SCIE). Analisou-se nos instantes iniciais um incêndio, por meio de simulação computacional no FDS, o desempenho de diversas configurações de compartimentação 
horizontal em um modelo representativo de uma sala de aula de um edifício padrão de dois pavimentos. Para o autor, a compartimentação é uma importante medida de proteção passiva capaz de confinar a ação do incêndio no ambiente de origem, e assim propiciar a garantia da segurança contra incêndio das edificações e seus ocupantes. A Figura 4 mostra o desenho esquemático da compartimentação seletiva proposta por Cunha (2016).

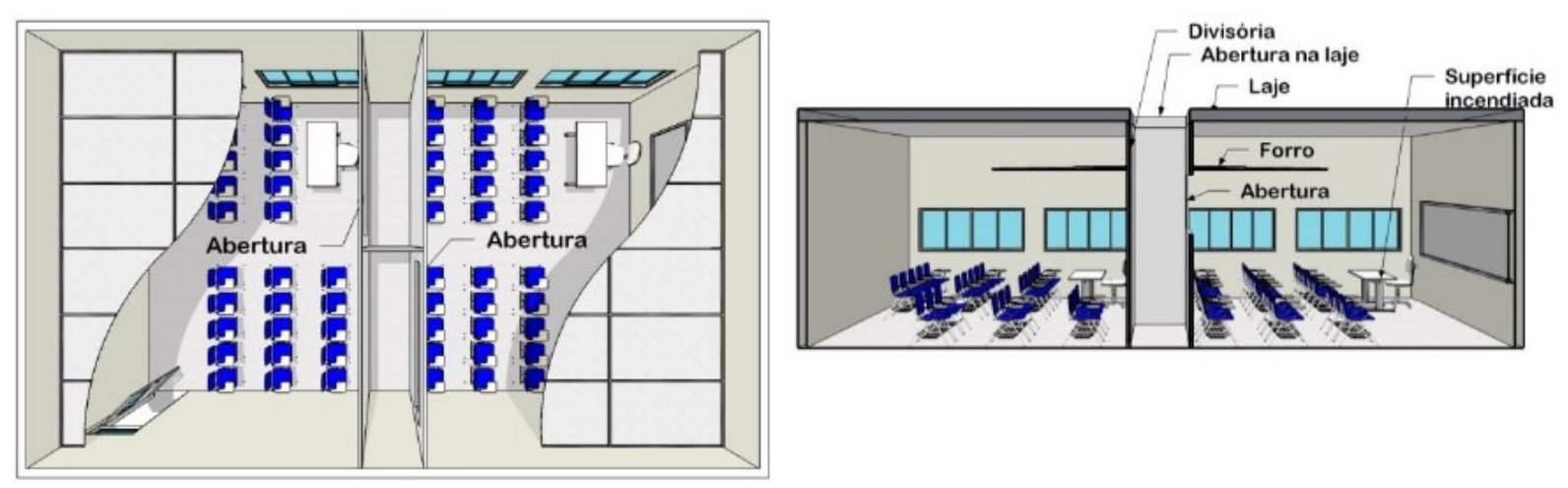

Figura 4 - Compartimentação seletiva proposta por Cunha (2016).

Fonte: Cunha, 2016.

Com esta pesquisa, Cunha (2016) constatou que a compartimentação proposta, sobretudo no caso de aberturas maiores para exaustão, foi capaz de aumentar significativamente o tempo necessário para a camada de fumaça ocupar todo o ambiente incendiado. Em uma situação real, isto proporcionaria aos ocupantes da edificação um tempo maior de evacuação culminando em um maior número de vidas salvas durante estes sinistros.

Entretanto, para o autor, quanto mais o modelo computacional tenta reproduzir a realidade, mais ele se afasta da prática projetual arquitetônica: o tempo de processamento demasiado, a falta de interface gráfica para a entrada de dados e templates pré-definidos, exigindo um elevado grau de conhecimento teórico para a correta descrição dos fenômenos físicos envolvido 
em um incêndio, se tornam os pontos negativos para o uso do FDS. (CUNHA, 2016).

Carlos et al. (2016), realizaram o estudo do desempenho do sistema de controle de fumaça de um edifício de 5 pavimentos, com ênfase na análise de um ambiente de grandes dimensões, conforme as normas portuguesas EN 1037-1 (2002) e EN 1991-1-4 (2010), Decreto-Lei de Portugal nº 220 (2008), Portaria $n^{\circ} 1532$ (2008), e a norma francesa IT-246 (2004), além de determinar o tempo de evacuação de pessoas desta edificação em situação de incêndio utilizando o método de cálculo proposto por Nelson e MacLennan (1995).

Posteriormente os autores realizaram uma análise numérica do escoamento de fumaça desta edificação em situação de incêndio com o auxilio do software FDS, a fim de se determinar o Fractional Effective Dose (FED), um índice que determina as condições de incapacitação de uma pessoa dependendo da concentração de gases provenientes dos produtos do incêndio (CARLOS et al., 2016), a visibilidade e a temperatura no ambiente.

Para Carlos et al. (2016) a realização do controle de fumaça em edificações é de suma importância para a preservação da vida, uma vez que a intoxicação pelos gases produzidos em um incêndio pode provocar a incapacitação dos ocupantes, dificultando a evacuação e em casos extremos provocando a morte dos mesmos. Com este estudo, os autores constaram que a legislação portuguesa apresenta ausência de informações específicas de valores para projeto de sistemas de controle de fumaça e, a partir da utilização do FDS, afirmam que o ambiente estudado merece análises mais criteriosas quanto à eficiência destes sistemas.

Mariani e Carlos (2016) desenvolveram um estudo de evacuação em uma edificação de dois pavimentos destinada ao uso de um restaurante, localizado na cidade de Brasília. Para isso foram considerados os cenários da edificação sob a ação de incêndio em sua situação real, e a situação hipotética de dimensionamento de saídas de emergência conforme as prescrições 
normativas brasileiras e portuguesas. Sendo que, a determinação do tempo de evacuação foi realizada conforme o método de Nelson e MacLennan (1995) e simulação computacional com o uso dos softwares FDS e Evac. Além disso, os autores ainda fizeram verificações de temperaturas, camada de fumaça e FED desenvolvidas durante a simulação computacional.

Com este estudo, Mariani e Carlos (2016) puderam identificar as principais diferenças na legislação brasileira e portuguesa, quanto aos cálculos de saídas de emergência deste tipo de edificação, além de comparar os resultados com os obtidos nas simulações computacionais. Com estes resultados os autores concluíram que as saídas de emergência na situação real da edificação se encontram em desacordo para ambas as normas.

Com as simulações realizadas, além de determinar o tempo de evacuação, os autores puderam estimar o número de vitimas fatais de um incêndio hipotético ocorrido nesta edificação. Esses resultados mostram que, mesmo atendendo as indicações das normas, ainda haveria vitimas fatais decorrentes do sinistro. Desta forma, Mariani e Carlos (2016) concluíram que uma evacuação segura em situação de incêndio não pode ser garantida somente pela aplicação das prescrições normativas em relação ao número de saídas de emergência e quantidade de unidades de passagem.

Hauser (2016) desenvolveu um estudo cujo objetivo foi avaliar a influência que um tanque contento óleo combustível (gasolina) em chamas tem sobre outro tanque adjacente considerado isolado pela ABNT NBR 17505-7. Para isso, o autor realizou simulações computacionais para quatro situações, variando a altura e diâmetro dos tanques e, avaliou, através da observação das temperaturas atingidas durante 0 incêndio, a condição a que 0 tanque adjacente esteve submetido. Com este estudo, Hauser (2016) constatou que a imposição da norma para que as distancias entre tanques seja em função do diâmetro dos mesmos é muito pertinente, uma vez que, que os tanques 
maiores apresentam maior transferência de calor e necessitando de maiores distâncias para manter a segurança.

Tabaczenski et al. (2017) desenvolveram um modelo computacional de um incêndio real em um compartimentado representando um escritório, baseado em um trabalho experimental encontrado na literatura, a fim de representar adequadamente o desenvolvimento de temperaturas no ambiente estudado. Para avaliar a importância da atribuição das características térmicas dos materiais não combustíveis (paredes, piso e teto) da simulação, os autores consideraram duas situações: (i) Situação 1: as paredes, teto e piso foram consideradas inertes; (ii) Situação 2: as paredes, teto e piso receberam suas respectivas propriedades.

Para os autores, no desenvolvimento dos modelos no FDS, a definição e obtenção dos dados referentes às propriedades dos materiais, tanto combustíveis quanto não combustíveis, se tornam a maior dificuldade enfrentada na utilização deste programa. No entanto, a não consideração destes parâmetros pode acarretar na obtenção de resultados incompatíveis com a realidade dos incêndios. (TABACZENSKI et al., 2017). Com os resultados obtidos, ao contrario do que ocorreu com a Situação 2, ficou evidente que a Situação 1 considerada não conseguiu representar adequadamente o desenvolvimento das temperaturas do incêndio estudado. Assim, Tabaczenski et al. (2017) constataram que o conhecimento das propriedades térmicas não só dos materiais combustíveis, mas também dos materiais não combustíveis envolvidos numa simulação computacional é de suma importância para a obtenção de resultados coerentes com as situações reais.

Kiryu (2017) desenvolveu um estudo cujo objetivo foi determinar a temperatura média na camada de gases quentes para diversos cenários de incêndio em um compartimento. Para isso, o autor desenvolveu um modelo computacional no FDS, baseado em um estudo experimental encontrado na 
Revista Científica do Corpo de Bombeiros Militar de Pernambuco

Seção 1 - Artigos Técnico Científicos

Artigo publicado no Vol.03 №7 - Edição de JUL a DEZ 2017 - ISSN 2359-4829

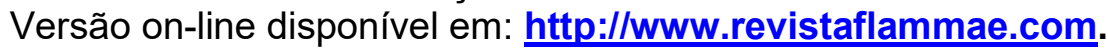

literatura, variando as dimensões das aberturas deste compartimento, e posteriormente comparou os resultados obtidos com valores obtidos experimental, analítica e empiricamente.

Para o autor, "a temperatura da camada de gases quentes é um dos critérios mais importantes para a Engenharia de segurança contra incêndios" e "a maior compreensão do fenômeno do fogo possibilita a prevenção de ocorrência de incêndios e redução de danos a estruturas e à saúde humana". (KIRYU, 2017). Com este estudo, Kiryu (2017) verificou que os modelos numéricos desenvolvidos no FDS produziram resultados mais próximos dos valores experimentais se comparados aos resultados analíticos e empíricos, mostrando a simulação computacional através deste software como uma ferramenta útil para determinar as temperaturas desenvolvidas na ocorrência de incêndios dentro de compartimentos.

Matos (2017) desenvolveu um estudo cujo objetivo foi analisar a vazão mássica, provocada por incêndios, entre ambientes conjugados interligados por uma abertura, simulando uma situação comum em residências de arquitetura moderna. Para isso, o autor desenvolveu três modelos (cuja geometria dos ambientes foi baseada em um estudo experimental encontrado na literatura) com diferentes geometrias de aberturas entre os compartimentos e posteriormente comparou os resultados obtidos com valores obtidos experimental e analiticamente.

Segundo o autor, as pesquisas voltadas para estudos da vazão mássica entre compartimentos fechados são importantes, visto que, a grande maioria das fatalidades relacionadas a intoxicação por fumaça ocorrem em ambientes distantes do foco de incêndio. Assim Matos (2017) observou que nos três casos analisados houve uma representatividade os dados experimentais pela simulação realizada no FDS. Para o autor, a forma mais eficiente para análise de incêndios compartimentados é a associação de conhecimento teórico, 
simulação numérica e correlações específicas, baseadas em experimentos, para cada caso estudado.

\section{ANÁLISE DOS ESTUDOS REALIZADOS}

Além destes estudos, Dolvitsch e Klein (2015) realizaram uma análise de três diferentes casos de estudos realizados com o auxílio dos softwares FDS, PyroSim e EVAC, tanto a nível nacional, quanto internacional, e apresentaram possíveis aplicações especificamente comerciais para este tipo de ferramenta.

Com este estudo, Dolvitsch e Klein (2015) demonstraram o potencial das ferramentas computacionais para a reprodução de incêndios reais, analise da eficiência do uso de sprinklers e, principalmente na simulação de evacuação de pessoas em caso de incêndio, uma vez que a realização deste tipo de ensaio real possui um alto risco à vida e elevado custo financeiro. Para os autores, apesar da validade dos resultados obtidos com a utilização dos softwares de simulação de incêndios ainda ser questionada (visto que estes foram desenvolvidas a partir de princípios teóricos simplificados), estas ferramentas vêm sendo amplamente utilizadas para reprodução de incêndios reais e sua eficácia está diretamente relacionada ao conhecimento do operador com relação à dinâmica de incêndios e às limitações do programa.

Desta forma, Dolvitsch e Klein (2015) concluíram que a simulação de evacuação de pessoas possibilita estimar a eficiência de rotas de fuga em edificações complexas, enquanto que a simulação do comportamento do incêndio pode auxiliar tanto na análise de diferentes geometrias de edificações (verificando a eficiência da compartimentação vertical e de outros sistemas passivos de combate a incêndios), quanto na verificação da melhor distribuição de sprinklers (com o objetivo de maximizar o combate em caso da ocorrência de sinistros e minimizar custos de instalação destes equipamentos), tornandose umas das potenciais aplicações comerciais para este tipo de ferramenta. 
Revista Científica do Corpo de Bombeiros Militar de Pernambuco

Seção 1 - Artigos Técnico Científicos

Artigo publicado no Vol.03 №7 - Edição de JUL a DEZ 2017 - ISSN 2359-4829

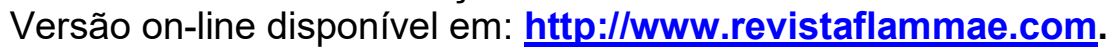

Apesar de todas as potencialidades deste software, a complexidade dos fenômenos físico-químicos decorridos de um incêndio abordados em sua programação (ainda que de forma simplificada), torna o grau de conhecimento teórico exigido para sua correta utilização bem mais elevado se comparado aos softwares baseados no modelo de zonas. Ademais, "A ausência de templates pré-configurados obriga o operador a atribuir valores, de difícil obtenção até mesmo na literatura especializada, às variáveis físico-químicas da combustão". (CUNHA, 2016).

Um dos fatores que influencia a eficiência do FDS é a simplicidade de sua malha numérica retilínea. Isso pode se tornar uma limitação em algumas situações, visto que, de maneira geral, a geometria de todos os objetos presentes na simulação (paredes, teto, piso, portas, móveis, pacotes combustíveis, etc.) deve ser representada por prismas de base retangular e orientanda apenas no eixo global do plano cartesiano. Caso a arquitetura do ambiente a ser reproduzido possua curvas, objetos rotacionados ou qualquer geometria mais complexa, estratégias deverão ser adotadas com o objetivo de ajustar o projeto ao padrão do software. (MCGRATTAN et al., 2016; BRUNETTO, 2015).

Além destas, dentre as dificuldades da utilização deste software descritas nos estudos apresentados, destacam-se:

- Não disponibilização de interface gráfica para entrada de dados, o que torna a modelagem de diferentes cenários demorada $\mathrm{e}$ trabalhosa. (CUNHA, 2016; TABACZENSKI et al., 2017);

- Ausência de um banco de dados para atribuição dos parâmetros necessários para uma simulação dos processos físicos de combustão de combustíveis sólidos: os resultados dos cálculos são sensíveis aos parâmetros físico-químicos atribuídos pelo usuário e as propriedades de materiais combustíveis reais são muitas vezes 
Revista Científica do Corpo de Bombeiros Militar de Pernambuco

Seção 1 - Artigos Técnico Científicos

Artigo publicado no Vol.03 №7 - Edição de JUL a DEZ 2017 - ISSN 2359-4829

Versão on-line disponivel em: http://www.revistaflammae.com.

desconhecidas ou de difícil obtenção. (RUSCHEL, 2011; CUNHA, 2016; TABACZENSKI et al., 2017);

- Tempo de processamento demasiado: dependendo da complexidade do modelo analisado e/ou da dimensão da malha utilizada, as simulações podem demorar horas ou até dias para serem concluídas. (RUSCHEL, 2011; FONTENELLE (2012); CARVALHO, 2013; MAZZONI e KLEIN, 2015; BRUNETTO, 2015; CUNHA, 2016; TABACZENSKI et al., 2017; KIRYU, 2017; MATOS, 2017);

- A validação dos modelos desenvolvidos ainda é muito dependente da realização de estudos experimentais para comparação de resultados obtidos. (CUNHA, 2016);

- Não prevê fenômenos mecânicos que ocorrem com os materiais ao serem submetidos a altas temperaturas, como a quebra de janelas de vidro por exemplo. A representatividade destes deve ser feita pelo usuário através de estratégias que causem efeitos semelhantes aos fenômenos na simulação, como por exemplo, criar uma abertura no lugar da janela quando esta atingir determinada temperatura. (BRUNETTO, 2015).

Destaca-se que a grande maioria destas limitações são amenizadas com o uso do software PyroSim, no entanto, diferente do FDS, este não é um programa gratuito.

Para Cunha (2016), "toda a dificuldade encontrada na elaboração do arquivo de entrada de dados é compensada pela diversidade dos resultados gerados". O usuário pode, dentre outros, obter leituras de: temperaturas de gases e objetos, altura da camada de fumaça, concentração de oxigênio e fumaça no ambiente, taxa de liberação de calor (em inglês Heat Release Rate, HRR), taxa de perda de massa de materiais combustíveis, comportamento da supressão do incêndio causado pelo uso de sprinklers, comportamento do 
incêndio causado pela abertura de portas e janelas ou pela presença de arcondicionado, ventiladores e/ou exaustores de ar, dentre uma infinidade de outros. (CUNHA, 2016; TABACZENSKI, 2017).

Além desta, observou-se outras vantagens da utilização deste software, tais como:

- É possível visualizar a propagação do incêndio e movimentação da fumaça através das animações gráficas geradas no SMV;

- Não há limite de compartimentos ou tamanho do domínio computacional a ser simulado: é possível realizar simulações não só de incêndios em edificações, mas também em grandes espaços abertos (como incêndios florestais), incêndios industriais, incêndios de poça, dentre outros;

- Permite a consideração de malhas de diferentes tamanhos em uma mesma simulação, possibilitando também a divisão de processamento em vários núcleos paralelamente. (FONTENELLE, 2012; CARVALHO, 2013);

- É possível determinar alguns parâmetros dependentes da temperatura, como condutividade e calor específico. (RUSCHEL, 2011);

- É possível parar e reiniciar simulações: o usuário pode criar um arquivo de reinicialização que para e armazena os cálculos, fazer alguns ajustes limitados e, em seguida, reiniciar o cálculo a partir desse ponto no tempo.

A Tabela 1 mostra o resumo dos estudos realizados no Brasil com o auxílio do software FDS, enfatizando o tipo de análise (diagnóstica ou prognóstica), tipo das edificações estudadas, principais objetivos e validação das pesquisas. 
Tabela 1: Resumo dos estudos apresentados

\begin{tabular}{|c|c|c|c|c|}
\hline $\begin{array}{c}\text { Autor (ano) / } \\
\text { Origem da } \\
\text { pesquisa }\end{array}$ & $\begin{array}{l}\text { Tipo de } \\
\text { análise }\end{array}$ & $\begin{array}{l}\text { Tipo da } \\
\text { edificação } \\
\text { analisada }\end{array}$ & $\begin{array}{c}\text { Principal objetivo do } \\
\text { estudo }\end{array}$ & Validação \\
\hline $\begin{array}{c}\text { Alves et al. (2008) / } \\
\text { UnB e CBMDF }\end{array}$ & Prognóstico & Comercial & $\begin{array}{c}\text { Determinar a influência da fumaça e da } \\
\text { temperatura na evacuação de pessoas } \\
\text { e a eficiência das orientações } \\
\text { normativas }\end{array}$ & Não houve \\
\hline $\begin{array}{l}\text { Braga e Landim } \\
(2008) \text { / CBMDF }\end{array}$ & Diagnóstico & Residencial & $\begin{array}{c}\text { Determinar a causa mais provável do } \\
\text { incêndio e testar hipóteses levantadas } \\
\text { pela perícia }\end{array}$ & Caso real \\
\hline $\begin{array}{l}\text { Rodrigues (2009) / } \\
\text { UFRGS }\end{array}$ & Prognóstico & $\begin{array}{l}\text { Residencial e } \\
\text { comercial }\end{array}$ & $\begin{array}{c}\text { Analisar a eficiência do sistema de } \\
\text { compartimentação vertical externa } \\
\text { segundo as exigências das normas } \\
\text { brasileiras }\end{array}$ & $\begin{array}{l}\text { Ensaio } \\
\text { experimental }\end{array}$ \\
\hline $\begin{array}{l}\text { Ruschel }(2011) / \\
\text { UFRGS, UnB e } \\
\text { CBMDF }\end{array}$ & $\begin{array}{l}\text { Diagnóstico } \\
\text { e } \\
\text { prognóstico }\end{array}$ & $\begin{array}{l}\text { Comercial } \\
\text { (Shopping) }\end{array}$ & $\begin{array}{c}\text { Reproduzir a dinâmica de incêndio e } \\
\text { determinar as temperaturas } \\
\text { desenvolvidas }\end{array}$ & Caso real \\
\hline $\begin{array}{l}\text { Fontenelle (2012) / } \\
\text { UFRJ }\end{array}$ & Prognóstico & $\begin{array}{l}\text { Tanques de } \\
\text { combustível }\end{array}$ & $\begin{array}{l}\text { Avaliar a segurança de tanques } \\
\text { metálicos de armazenamento de etanol } \\
\text { em situação de incêndio }\end{array}$ & Não houve \\
\hline $\begin{array}{l}\text { Carvalho (2013) / } \\
\text { UFRJ }\end{array}$ & Prognóstico & $\begin{array}{l}\text { Túneis } \\
\text { rodoviários }\end{array}$ & $\begin{array}{l}\text { Demonstrar a aplicabilidade do FDS } \\
\text { para análise de segurança em túneis } \\
\text { rodoviários em situação de incêndio }\end{array}$ & Não houve \\
\hline $\begin{array}{l}\text { Brunetto (2015) / } \\
\text { UFRGS }\end{array}$ & Prognóstico & $\begin{array}{l}\text { Instituição de } \\
\text { ensino } \\
\text { superior }\end{array}$ & $\begin{array}{c}\text { Analisar a propagação do fogo e } \\
\text { fumaça em uma situação hipotética de } \\
\text { incêndio }\end{array}$ & Não houve \\
\hline $\begin{array}{l}\text { Mazzoni e Klein } \\
(2015) \text { / UFRGS }\end{array}$ & Diagnóstico & $\begin{array}{l}\text { Não } \\
\text { informado }\end{array}$ & $\begin{array}{c}\text { Determinar a causa mais provável do } \\
\text { incêndio e testar hipóteses levantadas } \\
\text { pela perícia }\end{array}$ & Caso real \\
\hline $\begin{array}{l}\text { Centeno et al. (2015) / } \\
\text { UNISINOS e UFFS }\end{array}$ & Prognóstico & Residencial & $\begin{array}{l}\text { Determinar as temperaturas } \\
\text { desenvolvidas em um incêndio } \\
\text { compartimentado }\end{array}$ & $\begin{array}{c}\text { Ensaio } \\
\text { experimental }^{*}\end{array}$ \\
\hline Cunha (2016) / UFRN & Prognóstico & $\begin{array}{l}\text { Instituição de } \\
\text { ensino } \\
\text { superior }\end{array}$ & $\begin{array}{c}\text { Propor e analisar uma forma de } \\
\text { compartimentação horizontal seletiva }\end{array}$ & Não houve \\
\hline
\end{tabular}

Carlos et al. (2016) / CBMDF e

Universidade de

Coimbra/Portugal
Estudar o dimensionamento do sistema de controle de fumaça, de

Prognóstico Administrativo acordo com as condições prescritas na regulamentação e estimar do tempo de evacuação de pessoas

Não houve 
Revista Científica do Corpo de Bombeiros Militar de Pernambuco Seção 1 - Artigos Técnico Científicos

Artigo publicado no Vol.03 №7 - Edição de JUL a DEZ 2017 - ISSN 2359-4829

Versão on-line disponível em: http://www.revistaflammae.com.

\begin{tabular}{|c|c|c|c|c|}
\hline $\begin{array}{l}\text { Mariani e Carlos } \\
\text { (2016) / CBMDF e } \\
\text { Universidade de } \\
\text { Coimbra/Portugal } \\
\end{array}$ & Prognóstico & $\begin{array}{l}\text { Restaurante e } \\
\text { Áreas de } \\
\text { apoio }\end{array}$ & $\begin{array}{c}\text { Estudar o dimensionamento de saídas } \\
\text { de emergência e determinar o tempo } \\
\text { de evacuação de pessoas }\end{array}$ & Não houve \\
\hline $\begin{array}{c}\text { Hauser (2016) / } \\
\text { UFRGS }\end{array}$ & Prognóstico & $\begin{array}{l}\text { Tanques de } \\
\text { combustível }\end{array}$ & $\begin{array}{c}\text { Avaliar a influência que um tanque } \\
\text { contento óleo combustível em chamas } \\
\text { tem sobre outro tanque adjacente } \\
\text { considerado isolado pela ABNT NBR } \\
17505-7\end{array}$ & Não houve \\
\hline $\begin{array}{c}\text { Tabaczenski et al. } \\
\text { (2017) / UFPE }\end{array}$ & Prognóstico & Escritório & $\begin{array}{c}\text { Determinar as temperaturas } \\
\text { desenvolvidas em um incêndio } \\
\text { compartimentado }\end{array}$ & $\begin{array}{c}\text { Ensaio } \\
\text { experimental* }\end{array}$ \\
\hline Kiryu (2017) / UFRGS & Prognóstico & $\begin{array}{c}\text { Não } \\
\text { informado }\end{array}$ & $\begin{array}{c}\text { Determinar a temperatura média na } \\
\text { camada de gases quentes para } \\
\text { diversos cenários de incêndio em um } \\
\text { compartimento }\end{array}$ & $\begin{array}{l}\text { Ensaio } \\
\text { experimental }^{*} \mathrm{e} \\
\text { modelos } \\
\text { analíticos e } \\
\text { empíricos } \\
\end{array}$ \\
\hline $\begin{array}{c}\text { Matos (2017) / } \\
\text { UFRGS }\end{array}$ & Prognóstico & Residencial & $\begin{array}{c}\text { Analisar a vazão mássica, provocada } \\
\text { por incêndios, entre ambientes } \\
\text { conjugados interligados por uma } \\
\text { abertura }\end{array}$ & $\begin{array}{l}\text { Ensaio } \\
\text { experimental* } \\
\text { modelos } \\
\text { analíticos } \\
\end{array}$ \\
\hline
\end{tabular}

Fonte: Elaborado pelos autores, 2017.

A partir dos estudos apresentados constatou-se a grande variabilidade de aplicação deste software. É notório que a aplicação de estudos com simulação computacional de incêndios aliados com ensaios experimentais ainda é rara no Brasil. Observa-se que a maioria dos estudos realizados estiveram voltados para o prognóstico de edificações, mostrando o potencial deste software no auxílio de prevenção de incêndios e proteção à vida de seus ocupantes.

\section{CONSIDERAÇÕES FINAIS}

A partir dos estudos apresentados constatou-se a grande variabilidade de aplicação deste software, tanto para realização de prognósticos quanto para investigação de incêndios ocorridos. É importante salientar que este é apenas um dos diversos programas para simulação de incêndios existentes atualmente, sendo que sua apresentação neste artigo se deu pelo fato deste 
Revista Científica do Corpo de Bombeiros Militar de Pernambuco

Seção 1 - Artigos Técnico Científicos

Artigo publicado no Vol.03 №7 - Edição de JUL a DEZ 2017 - ISSN 2359-4829

Versão on-line disponível em: http://www.revistaflammae.com.

ser o mais recorrente, tanto na literatura técnico-cientifica nacional quanto internacional.

Dentre as potencialidades apresentadas, destacam-se a utilização do software no auxilio do desenvolvimento de estudos de: avaliação da propagação do incêndio em edificações, avaliação da eficiência da utilização de sistemas de proteção passiva e ativa, determinação de melhores localizações de rotas de fuga, determinação das dimensões e localização de aberturas, reconstituição de incêndios ocorridos, averiguação de hipóteses de origem e causas de incêndios, estimação do tempo necessário para evacuação de edificações, estimação de curvas de temperaturas de incêndios reais, estimação da altura da camada de fumaça. Além disso, os resultados de temperatura extraídos destes estudos podem servir de suporte na análise das estruturas em situação de incêndios reais, culminando em dimensionamentos mais coerentes com a realidade das construções.

Conclui-se que o FDS é uma ferramenta que se mostra adequada na simulação de incêndio em edificações permitindo simular diversos cenários sem os custos e riscos inerentes de ensaios experimentais. Sendo assim, quando adequadamente utilizada e ajustada esta ferramenta, permite a compreensão de como um incêndio afetará a edificação, auxiliando no correto dimensionamento das mesmas em Situação de Incêndio (SI) e, consequentemente na proteção a vida de seus ocupantes.

\section{REFERÊNCIAS}

ALVES, A. B. C. G.; CAMPOS, A. T.; BRAGA, G. C. B. - Simulação Computacional de Incêndio Aplicada ao Projeto de Arquitetura. In: SEMINÁRIO INTERNACIONAL NUTAU'2008 - Espaço Sustentável: Inovações em Edifícios e Cidades, Núcleo de Pesquisa em Tecnologia da Arquitetura e Urbanismo da Universidade de São Paulo (USP), São Paulo/SP (Brasil), 2008.

BRAGA, G. C. B.; LANDIM, H. R. O. - Investigação de Incêndio. In: SEITO, A. I.; GILL, A. A.; PANNONI, F. D.; ONO, R.; SILVA, S. B.; CARLO, U. D.; SILVA, 
V. P. - A segurança contra incêndio no Brasil. São Paulo: Projeto Editora, p.333-345, 2008.

BRUNETTO, L. O. - Simulação computacional de incêndios: uma aplicação no prédio da escola de engenharia nova da UFRGS. Trabalho de Diplomação em Engenharia Civil, Escola de Engenharia da Universidade Federal do Rio Grande do Sul (UFRGS), Porto Alegre/RS (Brasil), 105 p., 2015.

CARLOS, T. B.; MARIANI, L. M.; MORAES, H. H. Q. - Avaliação do desempenho de sistemas de controle de fumaça por modelagem numérica. Ignis: Revista Técnico Científica do Corpo de Bombeiros Militar de Santa Catarina, Florianópolis (Brasil), Edição Especial: Anais do XVI SENABOM, v.1, n.2, p. 3-16, 2016.

CARVALHO, J. E. C. - Aplicação de fluidodinâmica computacional para análise de segurança de túneis rodoviários sob incêndio. Dissertação de Mestrado em Engenharia Civil, Programa de Pós-graduação em Engenharia Civil, Universidade Federal do Rio de Janeiro (UFRJ), Rio de Janeiro/RJ (Brasil), 73 p., 2013.

CENTENO, F. R.; CASSOL, F.; RODRIGUES, E. E. C. - Validação de modelagem numérica empregando o Software Fire Dynamics Simulator para um ambiente habitacional em situação de incêndio. In: $3^{\circ} \mathrm{CILASCl}$, Congresso Ibero-Latino-Americano sobre Segurança Contra Incêndios, Porto Alegre/RS (Brasil), 2015.

COSTA, C. N.; SILVA, V. P. - Revisão histórica das curvas padronizadas de incêndio. In: SEMINÁRIO INTERNACIONAL NUTAU'2006 - Inovações Tecnológicas e Sustentabilidade, Núcleo de Pesquisa em Tecnologia da Arquitetura e Urbanismo da Universidade de São Paulo, São Paulo/SP (Brasil), 2006.

CUNHA, L. J. B. F. - O desempenho da compartimentação horizontal seletiva na promoção da segurança contra incêndio em edificações. Tese de Doutorado em Arquitetura e Urbanismo, Programa de Pós-graduação em Arquitetura e Urbanismo, Universidade Federal do Rio Grande do Norte (UFRN), Natal/RN (Brasil), 237 p., 2016.

DOLVITSCH, J. N.; KLEIN, D. L. - Segurança contra incêndios: simulação computacional. In: $3^{\circ} \mathrm{CILASCl}$, Congresso Ibero-Latino-Americano sobre Segurança Contra Incêndios, Porto Alegre/RS (Brasil), 2015.

FONTENELLE, F. M. A. - Análise Térmica em Estruturas de Tanques de Armazenamento de Etanol em Situação de Incêndio. Dissertação de Mestrado em Engenharia Civil, Programa de Pós-graduação em Engenharia 
Civil, Universidade Federal do Rio de Janeiro (UFRJ), Rio de Janeiro/RJ (Brasil), 112 p., 2012.

HAUSER, A. J. - Simulação computacional de incêndio em tanque contendo óleo combustível: avaliação em tanques isolados conforme NBR 17505-7. Trabalho de Diplomação em Engenharia Civil, Escola de Engenharia da Universidade Federal do Rio Grande do Sul (UFRGS), Porto Alegre - RS (Brasil), 65 p., 2016.

KIRYU, T. M. - Avaliação da temperatura média das camadas de gases em um compartimento em situação de incêndio: comparação de dados experimentais, resultados numéricos e de modelos analíticos e empíricos. Trabalho de Diplomação em Engenharia Mecânica, Escola de Engenharia da Universidade Federal do Rio Grande do Sul (UFRGS), Porto Alegre - RS (Brasil), 25 p., 2017.

MARIANI, L. M.; CARLOS, T. B. - Estudo de evacuação em edificação em Brasília com o uso do FDS-EVAC. Ignis: Revista Técnico Científica do Corpo de Bombeiros Militar de Santa Catarina, Florianópolis (Brasil), Edição Especial: Anais do XVI SENABOM, v.1, n.2, p. 120-134, 2016.

MATOS, L. V. - Estudo numérico do escoamento de gases por uma abertura durante um incêndio em ambiente conjugado. Trabalho de Diplomação em Engenharia Mecânica, Escola de Engenharia da Universidade Federal do Rio Grande do Sul (UFRGS), Porto Alegre - RS (Brasil), 25 p., 2017.

MAZZONI, F.; KLEIN, D. L.- Análise da Propagação de Incêndio em Prédios Altos através da Simulação Computacional. In: $3^{\circ} \mathrm{CILASCl}$, Congresso Ibero-Latino-Americano sobre Segurança Contra Incêndios, Porto Alegre/RS (Brasil), 2015.

MCGRATTAN, K.; HOSTIKKA, S.; MCDERMOTT, R.; FLOYD, J.; WEINSCHENK, C.; OVERHOLT, K. - Fire Dynamics Simulator - User's Guide: Sixth Edition. NIST - Special Publication 1019: National Institute of Standards and Technology - NIST \& Technical Research Centre of Finland VTT, Maryland (EUA), 2016.

NELSON, H.; MACLENNAN, H. - Emergency Movement. In: DININNO, P. and others. SFPE Handbook of Fire Protection Engineering. 7. ed. National Fire Protection Association: Quincy Mass, 1995.

RODRIGUES, E. E. C. Análise da eficiência do sistema de compartimentação vertical externa por afastamento entre janelas e por projeções horizontais segundo as exigências normativas brasileiras. 
Dissertação de Mestrado em Engenharia Civil, Programa de Pós-graduação em Engenharia Civil, Universidade Federal do Rio Grande do Sul (UFRGS), Porto Alegre/RS (Brasil), 178 p., 2009.

RUSCHEL, F. - Avaliação da utilização de ferramentas de simulação computacional para reconstituição de incêndios em edificações de concreto armado: aplicação ao caso Shopping Total em Porto Alegre RS. Dissertação de Mestrado em Engenharia Civil, Programa de Pósgraduação em Engenharia Civil, Universidade Federal do Rio Grande do Sul (UFRGS), Porto Alegre/RS (Brasil), 2011, 131 p.

SEITO, A. I.; GILL, A. A.; PANNONI, F. D.; ONO, R.; SILVA, S. B.; CARLO, U. D.; SILVA, V. P. - A segurança contra incêndio no Brasil. São Paulo: Projeto Editora, 496 p., 2008.

TABACZENSKI, R.; PIRES, T. A. C.; SILVA, J. J. R.; NEGREIROS, R. Simulação computacional de um incêndio natural compartimentado: validação com um estudo experimental. In: $4^{\circ} \mathrm{CILASCI}$, Congresso IberoLatino-Americano sobre Segurança Contra Incêndios, Recife/PE (Brasil), 2017. 